\title{
Exercise-induced AMPK and pyruvate dehydrogenase regulation is maintained during short-term low-grade inflammation
}

\author{
Rasmus Sjørup Biensø • Jesper Olesen • Line van Hauen • \\ Simon Meinertz • Jens Frey Halling • Lasse Gliemann • \\ Peter Plomgaard • Henriette Pilegaard
}

Received: 5 February 2014 /Revised: 25 February 2014 / Accepted: 7 March 2014 /Published online: 2 April 2014

(C) The Author(s) 2014. This article is published with open access at Springerlink.com

\begin{abstract}
The aim of the present study was to examine the effect of lipopolysaccharide (LPS)-induced inflammation on AMP-activated protein kinase (AMPK) and pyruvate dehydrogenase (PDH) regulation in human skeletal muscle at rest and during exercise. Nine young healthy physically inactive male subjects completed two trials. In an LPS trial, the subjects received a single LPS injection ( $0.3 \mathrm{ng} / \mathrm{kg}$ body weight) and blood samples and vastus lateralis muscle biopsies were obtained before and $2 \mathrm{~h}$ after the LPS injection and immediately after a 10-min one-legged knee extensor exercise bout performed approximately $2^{\frac{1}{2} \mathrm{~h}} \mathrm{~h}$ after the LPS injection. The exercise bout with muscle samples obtained before and immediately after was repeated in a control trial without LPS injection. The plasma tumor necrosis factor $\alpha$ concentration increased 17 -fold $2 \mathrm{~h}$ after LPS relative to before. Muscle lactate and muscle glycogen were unchanged from before to $2 \mathrm{~h}$ after LPS and exercise increased muscle lactate and decreased muscle glycogen in the control $(P<0.05)$ and the LPS $(0.05 \leq P<0.1)$ trial with no differences between the trials. AMPK, acetyl-CoA carboxylase (ACC) and PDH phosphorylation as well as PDHa activity were unaffected $2 \mathrm{~h}$ after LPS relative to before. Exercise decreased $(P<0.05) \mathrm{PDH}$ and
\end{abstract}

R. S. Biensø - J. Olesen • L. van Hauen · S. Meinertz • J. F. Halling • H. Pilegaard $(\varangle)$

Centre of Inflammation and Metabolism, The Center for Physical Activity Research and August Krogh Centre, Department of Biology, University of Copenhagen, Universitesparken 13,

2100 Copenhagen Ø, Denmark

e-mail: HPilegaard@bio.ku.dk

L. Gliemann

Department of Nutrition Sport and Exercise, University of

Copenhagen, Copenhagen, Denmark

P. Plomgaard

Centre of Inflammation and Metabolism and The Centre for Physical Activity Research, Department of Clinical Biochemistry,

Rigshospitalet, Copenhagen, Denmark increased $(P<0.05)$ AMPK and ACC phosphorylation as well as increased $(P<0.05)$ PDHa activity similarly in the LPS and control trial. In conclusion, LPS-induced inflammation does not affect resting or exercise-induced AMPK and PDH regulation in human skeletal muscle. This suggests that metabolic flexibility during exercise is maintained during short-term low-grade inflammation in humans.

Keywords LPS $\cdot$ TNF $\alpha \cdot$ Skeletal muscle $\cdot$ Substrate oxidation $\cdot$ Human $\cdot$ AMPK $\cdot$ Exercise

\section{Introduction}

Skeletal muscle has an extraordinary ability to regulate substrate choice and utilization according to availability [11, 32]. The exercise-induced enhancement of glucose and fat oxidation in skeletal muscle ensures ATP production for muscle contractions, and the interaction between fatty acids and glucose regulates the relative fatty acid and glucose oxidation and contributes to efficient substrate utilization [32]. Regulation of substrate choice and substrate utilization may however be influenced by metabolic changes and contribute to metabolic dysfunction. For example, chronically elevated plasma free fatty acid (FFA) levels will inhibit glucose oxidation and elevated plasma glucose may inhibit fat oxidation in skeletal muscle [19, 23, 27, 32]. Similarly, metabolically related diseases are often associated with low-grade inflammation characterized by chronically elevated levels of circulating cytokines [25] like the proinflammatory cytokine tumor necrosis factor (TNF) $\alpha$. Previous studies have linked $\mathrm{TNF} \alpha$ to insulin resistance in rat and human skeletal muscle [17, 30], as well as indicated TNF $\alpha$-mediated effects on substrate utilization [35, 40, 47].

The pyruvate dehydrogenase (PDH) complex has a key position in the regulation of substrate choice as it catalyzes the decarboxylation of pyruvate to acetyl $\mathrm{CoA}$, which represents 
the entry of carbohydrate-derived substrate into the mitochondria for oxidation [33]. In accordance, exercise has been shown to induce a rapid increase in the activity of PDH in the active form (PDHa) in human skeletal muscle [18] concomitant with increased glucose oxidation [31]. Furthermore, elevated plasma FFA has been shown to be associated with a reduced exercise-induced increase in PDHa activity in human skeletal muscle [20] supporting that PDH contributes to regulating substrate utilization during exercise as part of the interaction between fatty acids and carbohydrates $[32,33]$. The PDHa activity is thought mainly to be regulated by phosphorylation of the PDH-E1 $\alpha$ subunit $[22,28]$ determined by the activity of PDH kinases (PDK), which phosphorylate and inactivate the enzyme and PDH phosphatases (PDP), which dephosphorylate and activate PDH. Previous studies have shown that the PDK4 protein content is up-regulated in rat and/or human skeletal muscle by fasting and high-fat diet $[26,46]$ and this regulation has been suggested to contribute to the associated changes in PDHa activity [16]. Although the PDK4 protein content has been shown to be unaffected during even prolonged exercise, the PDK4 protein content has been demonstrated to be rapidly regulated in human skeletal muscle by carbohydrate availability [20] indicating a potential role of acute changes in PDK4 protein content in PDH regulation.

Several previous studies suggest that inflammation influences PDH regulation. Repeated Escherichia coli injections in rats have been shown to reduce the concentration of active PDH complex and increase PDK activity [39, 40]. Moreover, the observations that treatment with $\mathrm{TNF} \alpha$ reduced PDH activity in rat cardiomyocytes [47] and human immune cells [36] as well as the finding that treatment with $\mathrm{TNF} \alpha$ binding protein alleviated the effects of inflammation on PDH activity [40] indicate that TNF $\alpha$ influences PDH regulation. These findings are further supported by a study showing that lipopolysaccharide (LPS) infusion for $24 \mathrm{~h}$ decreased PDHa activity and increased PDK4 protein content in rat skeletal muscle [13]. On the other hand, local infusion of LPS or TNF $\alpha$ in one leg did not change resting PDH-E1 $\alpha$ phosphorylation in human skeletal muscle $[6,9]$, which may suggest that the impact of inflammation on PDH regulation at rest depends on species, dose, or duration of the treatment.

The intracellular energy sensor, AMP-activated protein kinase (AMPK), is also a key factor in the regulation of substrate utilization. AMPK activity is increased both by AMP-mediated allosteric regulation and by phosphorylation [44] leading to stimulation of several downstream processes aiming at increasing ATP production. In accordance, exercise increases AMPK phosphorylation and activity in skeletal muscle leading to an enhancement of fat oxidation in skeletal muscle through AMPK-mediated phosphorylation and inactivation of acetyl-CoA carboxylase (ACC) [43]. As
ACC catalyzes the production of malonyl CoA, an inactivation of ACC leads to reduced production of malonylCoA with concomitantly less inhibition of carnitine palmitoyltransferase I and an increased fatty acid oxidation [15]. AMPK has been suggested to have anti-inflammatory effects [14], and AMPK phosphorylation has been reported to increase in human skeletal muscle after an LPS injection, although a concomitant increase in ACC phosphorylation was not observed [3]. This may suggest that inflammation modifies AMPK-mediated intracellular signaling in resting skeletal muscle.

Although previous studies indicate that inflammation affects PDH and AMPK regulation, it is yet unresolved how inflammation influences exercise-induced AMPK and PDH regulation in human skeletal muscle. Therefore, the aim of the present study was to test the hypothesis that LPS-induced short-term inflammation impairs AMPK and PDH regulation in human skeletal muscle at rest and in response to an acute exercise bout.

\section{Methods}

\section{Subjects}

Nine physically inactive young healthy male subjects in the range from 20 to 26 years of age with an average body mass index of $25.6 \pm 3.7($ mean \pm SD) participated in the study. The subjects were physically active less than $1 \mathrm{~h}$ per week. Each subject underwent a health examination by a medical doctor. The subjects could participate in the study if the $\mathrm{VO}_{2 \max }$ was less than $45 \mathrm{ml} \mathrm{min}^{-1} \mathrm{~kg}^{-1}$ and was approved by the medical doctor. This fitness level was chosen to obtain healthy but untrained subjects to avoid any potential effects of training status on the effect of short-term inflammation on AMPK and PDH regulation. A group of endurance trained subjects also completed the experimental trials, but for another purpose than the present study and are therefore not include in the present study. The subjects were given both written and oral information about the study and the subjects gave their written consent to participate in the study. The study was performed according to the Declaration of Helsinki and approved by the Copenhagen and Frederiksberg Ethical committee in Denmark (H-1-2012-108).

\section{Pre-testing}

The $\mathrm{VO}_{2 \max }$ was measured for each subject using an incremental ergometer bicycle test (Monarch Ergomedic 839E) for use as inclusion criteria. In addition, Watt max $_{\text {ax }}$ was determined during an incremental one-legged knee extensor exercise test on a modified ergometer bicycle as previously described [29]. 
The Watt max $_{\text {was }}$ used to determine the resistance during the experimental trials.

\section{Experimental protocol}

The subjects completed a LPS trial and a control trial separated by a least 7 days. For both trials, the subjects were instructed to eat a carbohydrate rich meal $1 \mathrm{~h}$ before arriving to the laboratory.

LPS trial After arriving to the laboratory, a catheter was placed in the femoral artery and in the femoral vein of one leg and a venflon (BD, East Rutherford, NJ, USA) was placed in an antecubital vein in the forearm. Blood samples were obtained from the femoral catheters and a muscle biopsy was obtained from the vastus lateralis muscle using the needle biopsy method [8] with suction. Insertions for biopsies were made under local anesthesia (Lidocaine, AstraZeneca, Södertälje, Sweden). A LPS solution $(100 \mathrm{ng} / \mathrm{ml})$ was either freshly prepared from a LPS stock (The Clinical Center, Critical Care Medicine Department, Bethesda, MD, USA) or used within a week from the preparation with storage at $-20^{\circ} \mathrm{C}$. An intravenous injection of $0.3 \mathrm{ng} / \mathrm{kg}$ LPS was given through an arm venflon approximately $2.5 \mathrm{~h}$ after the subjects had eaten breakfast. Additional blood samples were obtained 30,60, 90, and $120 \mathrm{~min}$ after LPS injection and additional muscle biopsies at 1 and $2 \mathrm{~h}$ after LPS was given. The 1-h biopsy, all venous blood samples and arterial blood samples obtained at 30,60 and 90 min after the LPS injection are not used in the present study except the venous sample before LPS for comparison of the arterial and venous $\mathrm{TNF} \alpha$ level. After the 2 -h blood and tissue sampling, the subjects were transferred to a chair connected to a onelegged knee extensor ergometer bicycle with the back of the chair lying down. The right foot of the subject was tied to a rod connected to the crank set of the modified ergometer bicycle. The subjects first performed 1-min passive knee extensions to warm up the leg followed by 5 -min exercise at $50 \%$ of Watt max $_{\text {max }}$ and 5 -min exercise at $60 \%$ of Watt max $_{\text {. Additional blood }}$ samples were obtained $8 \mathrm{~min}$ into the exercise and an additional muscle biopsy was obtained from the vastus lateralis muscle of the working leg immediately as the exercise was terminated after $10 \mathrm{~min}$ of exercise.

Individual insertions were made for each biopsy. Visual fat, connective tissue, and blood were removed from the biopsies, which were quickly frozen in liquid nitrogen. The muscle biopsy piece used for PDHa activity was frozen in liquid nitrogen within $\sim 15 \mathrm{~s}$. The muscle biopsies were stored at $-80{ }^{\circ} \mathrm{C}$. The blood was collected in EDTA containing tubes, which were centrifuged and plasma was collected and stored at $-80^{\circ} \mathrm{C}$.

Ear temperature, mean arterial blood pressure (MAP), and heart rate were recorded every $15 \mathrm{~min}$ until $3 \mathrm{~h}$ after the LPS injection. MAP monitoring continued until at least $4 \mathrm{~h}$ after the LPS injection to insure that normal blood pressure regulation was re-established.
Control trial After arriving to the laboratory, a venflon was inserted in a vein in the forearm and a blood sample was obtained through the venflon (BD). In addition, a muscle biopsy was obtained from the vastus lateralis muscle as described above. The subjects were placed in the chair connected to the onelegged knee extensor ergometer bicycle with the back of the chair lying down. The right leg of the subject was tied to the modified ergometer bicycle and $1 \mathrm{~min}$ of passive knee extensions was performed followed by 5 -min exercise at $50 \%$ Watt $_{\max }$ and 5 -min exercise at $60 \% \mathrm{Watt}_{\max }$ as in the LPS trial. An additional blood sample was drawn after $8 \mathrm{~min}$ of exercise and an additional vastus lateralis muscle biopsy was obtained from the working leg immediately after $10 \mathrm{~min}$ of exercise. Blood and muscle biopsies were handled as described for the LPS trial above.

\section{Plasma analyses}

Plasma glucose and insulin The blood was analyzed immediately for blood glucose (ABL, Radiometer 725 series Acidbase Analyzer, Denmark) and insulin was measured at The Department of Clinical Biochemistry at Rigshospitalet, Copenhagen, Denmark.

Plasma $T N F \alpha$ The plasma TNF $\alpha$ was determined using a MSD multi-spot 96 wells plate with pre-coated antibodies (MesoScaleDiscovery, Gaithersburg, ML, USA). The plates were measured on MSD Sector Image 2400 plate reader. The data were analyzed using the Discovery Workbench 3.0 (MSD). The results were converted to a concentration by use of a standard curve constructed from a serial dilution of recombinant TNF $\alpha$ run alongside on each plate.

\section{Muscle analyses}

Dividing of muscle tissue A piece of wet weight muscle tissue was chipped off and used for the PDHa activity analysis. An additional part of the muscle biopsies was freeze-dried for at least $48 \mathrm{~h}$ and these samples were dissected free from visual blood and connective tissue under the microscope. The freezedried muscle tissue was weighted out for the different analyses and stored at $-80^{\circ} \mathrm{C}$.

Muscle glycogen The muscle glycogen concentration was determined on freeze-dried muscle tissue as glycosyl units after acid hydrolysis as previously described [24].

Muscle lactate PCA extract was made on freeze-dried muscle tissue as previously described [7]. Muscle lactate was measured using the auto-fluorescence ability of NADH as previously described [7].

SDS-PAGE and Western blotting The freeze-dried muscle was homogenized using a Tissue LyserII (Qiagen, Hilden, 
Germany) and the homogenized muscle samples were made into lysates as previously described [38]. The protein concentration was determined with the bicinchoninic acid method (Pierce, ThermoScientific, Rockford, IL, USA) using BSA as a standard.

The lysate samples were loaded on hand casted gels (7.5$10 \%)$. After the gel electrophoresis, the proteins were blotted from the gel to a PVDF membrane (Millipore, Bedford, USA), blocked in $3 \%$ fish gelatin solution and incubated with antibodies. The protein content and phosphorylation level were determined using antibodies towards AMPK $\mathrm{Thr}^{172}$ phosphorylation (2535; Cell Signaling Technology, Berverly, MA, USA), ACC Ser ${ }^{221}$ phosphorylation (07-303; Millipore, Bedford, USA), PDH Ser ${ }^{293}$ (site 1), PDH Ser ${ }^{300}$ (site 2), PDH $\mathrm{Se}^{295}$ (site 4) phosphorylation, PDH-E1 $\alpha$ protein, AMPK $\alpha 2$ protein, and PDK4 protein (provided by Graham Hardie, Dundee University, Dundee, UK). ACC protein content was detected using streptavidin-HRP (Dako, Glostrup, Denmark). The bands on the membranes were visualized with ECL reagent (Millipore, Billerica, MA, USA) in a digital image system (GE healthcare, München, DE).

PDHa activity The PDHa activity was determined as previously described $[10,12,31])$. In brief, muscle homogenate was prepared on ice from wet weight muscle tissue using a glass homogenizer (Kontes, Vineland, NJ, USA). Pyruvate was converted to acetyl CoA followed by determination of the acetyl CoA content by use of a radioactive assay. The PDHa activity was determined as the rate of conversion of pyruvate to acetyl $\mathrm{CoA}$ and normalized to the total creatine content in each sample as previously described [34].

\section{Statistics}

Values presented are means \pm SE. A paired $t$ test was used to test the effect of LPS at rest. A two-way ANOVA with repeated measures was used to evaluate the effect of LPS and exercise. The data were $\log$ transformed if normality or equal variance test failed. If a significant main effect was detected, the student Newman-Keuls test was used to locate differences. Differences are considered significant at $P<0.05$ and a tendency is reported for $0.05 \leq P<0.1$. Statistical calculations were performed using SigmaPlot 11.0 (Systat Software, Inc, San Jose, CA, USA).

\section{Results}

Physical parameters

The mean arterial pressure was stable around $85-90 \mathrm{mmHg}$ and the ear temperature was unchanged around $37.0-37.6{ }^{\circ} \mathrm{C}$. The heart rate increased $(P<0.05)$ from $63 \pm 3$ before LPS to $83 \pm 4$ beats/min $3 \mathrm{~h}$ after the LPS injection (Table 1).
Plasma parameters

\section{Plasma glucose and insulin}

The arterial plasma glucose concentration decreased $(P<0.05)$ $2 \mathrm{~h}$ after LPS relative to before the LPS injection. Exercise did not change the plasma glucose concentration in the LPS trial (Table 1).

The arterial plasma insulin concentration decreased $(P<0.05) 2 \mathrm{~h}$ after LPS injection relative to before LPS. Exercise did not affect the plasma insulin level in the LPS trial (Table 1).

\section{Plasma $T N F \alpha$}

Plasma TNF $\alpha$ was determined as a measure of the LPSinduced inflammation. The plasma TNF $\alpha$ concentration before LPS injection was similar in the femoral artery and femoral vein suggesting that arterial and venous levels can be compared at least in a non-inflammatory state. The arterial plasma TNF $\alpha$ concentration increased $(P<0.05) \sim 17$-fold $2 \mathrm{~h}$ after LPS injection relative to before LPS. Exercise did not change the plasma TNF $\alpha$ concentration in either trial. The arterial plasma TNF $\alpha$ concentration was $13-15$-fold higher $(P<0.05)$ in the LPS trial than the venous plasma TNF $\alpha$ in the control trial before and at the end of exercise (Table 2).

Muscle analyses

Muscle glycogen

The muscle glycogen concentration was unaffected from before LPS injection to $2 \mathrm{~h}$ after LPS. Exercise reduced $(P<0.05)$ muscle glycogen $27 \%$ in the control trial and tended to reduce $(0.05<P<0.1)$ muscle glycogen $6 \%$ in the LPS trial.

Table 1 Physiological and plasma parameters in the LPS trial

\begin{tabular}{llll}
\hline & Pre & $2 \mathrm{~h}$ LPS/pre exercise & $3 \mathrm{~h} \mathrm{LPS}$ \\
\hline Temperature $\left({ }^{\circ} \mathrm{C}\right)$ & $37.4 \pm 0.2$ & $37.3 \pm 0.1$ & $37.6 \pm 0.2$ \\
MAP $(\mathrm{mmHg})$ & $87.8 \pm 2.9$ & $88.0 \pm 3.4$ & $87.9 \pm 3.6$ \\
Heart rate (BPM) & $63 \pm 3$ & $68 \pm 4$ & $86 \pm 4^{*}$ \\
$\begin{array}{c}\text { Arterial plasma glucose } \\
\quad(\mathrm{mmol} / \mathrm{l})\end{array}$ & $6.4 \pm 0.6$ & $5.0 \pm 0.1^{*}$ & $4.9 \pm 0.2$ \\
$\begin{array}{c}\text { Arterial plasma insulin } \\
(\mathrm{pmol} / \mathrm{l})\end{array}$ & $135.8 \pm 18.2$ & $65.3 \pm 10.8^{*}$ & $69.3 \pm 8.9$ \\
\hline
\end{tabular}

Ear temperature $\left({ }^{\circ} \mathrm{C}\right)$, mean arterial pressure (MAP; $\mathrm{mmHg}$ ), and heart rate (beats/min) before (pre-LPS) and $2 \mathrm{~h}(2 \mathrm{~h} \mathrm{LPS})$ and $3 \mathrm{~h}(3 \mathrm{~h} \mathrm{LPS})$ after a single LPS injection as well as arterial glucose (mmol/l) and arterial insulin (pmol/l) at pre-LPS, $2 \mathrm{~h}$ LPS corresponding to before exercise (pre-exercise) and at $8 \mathrm{~min}$ of exercise (exercise). The values are mean $\pm \mathrm{SE}$

$* P<0.05$ (significantly different from pre-LPS) 
Table 2 Plasma TNF $\alpha$ concentrations

\begin{tabular}{lllll}
\hline & & Pre-LPS & 2 h LPS/pre-exercise & Exercise \\
\hline TNF $\alpha$ (ng/l) & Control & - & $0.97 \pm 0.1$ & $1.0 \pm 0.1$ \\
& LPS & $0.90 \pm 0.1$ & $15.5 \pm 1.6^{*} \#$ & $13.6 \pm 1.3^{*} \#$
\end{tabular}

Arterial (LPS trial) and venous (control trial) plasma tumor necrosis factor $(\mathrm{TNF}) \alpha(\mathrm{ng} / \mathrm{l})$ concentration before a single LPS injection (pre-LPS) and $2 \mathrm{~h}$ after the LPS injection corresponding to before exercise $(2 \mathrm{~h} \mathrm{LPS} /$ preexercise) and $8 \mathrm{~min}$ into an one-legged knee extensor exercise bout (exercise). The values are mean $\pm \mathrm{SE}$

${ }^{*} P<0.05$ (significantly different from pre-LPS); $\# P<0.05$ (significantly different from control at the given time point)

There was no significant difference in the muscle glycogen concentration between the two trials neither before nor after exercise (Table 3).

\section{Muscle lactate}

Muscle lactate did not change from before the LPS injection to $2 \mathrm{~h}$ after LPS. Exercise increased $(P<0.05)$ muscle lactate 6.8fold in the control trial and tended to increase $(0.05 \leq P<0.1)$ muscle lactate 4.9 -fold in the LPS trial with no difference between the two trials neither before exercise nor after exercise (Table 3).

\section{AMPK and ACC phosphorylation}

There was no difference in AMPK $\mathrm{Thr}^{172}$ and ACC Ser ${ }^{221}$ phosphorylation in skeletal muscle before and $2 \mathrm{~h}$ after LPS injection (Fig. 1a, c).

The exercise bout increased $(P<0.05)$ skeletal muscle AMPK phosphorylation $\sim 3$-fold and ACC phosphorylation 6-7-fold in the control and LPS trial with no difference in the responses between the trials. The AMPK and ACC

Table 3 Muscle glycogen and lactate concentrations

\begin{tabular}{lllcl}
\hline & & Pre-LPS & $\begin{array}{l}2 \mathrm{~h} \mathrm{LPS} / \\
\text { pre-exercise }\end{array}$ & Post-exercise \\
\hline $\begin{array}{lllll}\text { Glycogen } \\
(\mathrm{mmol} \mathrm{kg}\end{array}$ & Control $\mathrm{dw})$ & - & $365 \pm 38$ & $267 \pm 44^{*}$ \\
$\begin{array}{l}\text { Lactate } \\
(\mathrm{mmol} \mathrm{kg}\end{array}$ & LPS & $329 \pm 32$ & $391 \pm 49$ & $367 \pm 35^{*}$ \\
& Control & - & $9.7 \pm 1.9$ & $66.4 \pm 15.6^{*}$ \\
& LPS & $10.9 \pm 1.3$ & $10.8 \pm 1.4$ & $53.2 \pm 13.3^{* *}$ \\
\hline
\end{tabular}

Glycogen ( $\mathrm{mmol} \mathrm{kg}^{-1}$ dry weight) and lactate ( $\mathrm{mmol} \mathrm{kg}^{-1}$ dry weight) concentration in the vastus lateralis muscle before a single injection of LPS (pre-LPS), $2 \mathrm{~h}$ after the LPS injection corresponding to before exercise ( $2 \mathrm{~h} \mathrm{LPS} /$ pre-exercise), and immediately after $10 \mathrm{~min}$ of onelegged knee extensor exercise (post-exercise). The values are mean $\pm \mathrm{SE}$ $* P<0.05$ (significantly different from pre-LPS); $* * 0.05 \leq P<0.1$ (tends to be significantly different from pre-LPS) phosphorylation levels were similar in the two trials both before and after exercise (Fig. 1b, d).

\section{PDK4 protein}

The PDK4 protein content in skeletal muscle was unchanged by LPS injection (pre-LPS, $0.98 \pm 0.15 ; 2$ h LPS, $1.11 \pm 0.06$ ) (Data not shown).

Exercise did not affect the PDK4 protein content in skeletal muscle and there was no difference between the control and LPS trial (control, pre-exercise, $1.29 \pm 0.13$; control, postexercise, $1.12 \pm 0.14$; LPS, pre-exercise, $1.11 \pm 0.06$; LPS, post-exercise, $1.14 \pm 0.11$ ).

\section{PDH-E1/ phosphorylation}

PDH-E1 $\alpha$ phosphorylation at $\mathrm{Ser}^{293}, \mathrm{Ser}^{300}$, and $\mathrm{Ser}^{295}$ was unchanged $2 \mathrm{~h}$ after LPS injection relative to before (Fig. 2a, c, e).

Exercise decreased $(P<0.05)$ the PDH-E1 $\alpha$ phosphorylation at site $\operatorname{Ser}^{293} 40-50 \%$, site ${ }^{300} 60-70 \%$, and site $\operatorname{Ser}^{295}$ $30-40 \%$ in the control and LPS trial with no difference in the responses between the trials. The PDH-E1 $\alpha$ phosphorylation level was for each of the three sites similar in the control and LPS trial both before and after exercise (Fig. 2b, d, f).

\section{PDHa activity}

The PDHa activity was unchanged $2 \mathrm{~h}$ after LPS injection relative to before LPS. Exercise increased $(P<0.05)$ the PDHa activity $\sim 1$. 8 -fold in the control trial and $\sim 2$.2-fold in the LPS trial with no difference in the response between the trials. The PDHa activity was similar in the two trials both before and after exercise (Fig. 3).

\section{Discussion}

The main findings of the present study are that LPS-induced inflammation with elevated plasma TNF $\alpha$ concentration does not affect the exercise-induced AMPK and PDH regulation in human skeletal muscle. In addition, short-term inflammation does not affect AMPK and PDH regulation at rest.

The present human study used a single LPS injection to induce a controlled inflammation in young volunteers as a model for low-grade inflammation as frequently used [4, 5, $36,37]$. The present observation that the LPS injection increased the plasma TNF $\alpha$ concentration 17-fold to $\sim 15 \mathrm{ng} / 1$ $2 \mathrm{~h}$ after the LPS injection is in accordance with several previous studies $[4,5,37]$ and shows that the anticipated inflammatory state was obtained.

The observation that skeletal muscle PDHa activity and PDH phosphorylation did not change $2 \mathrm{~h}$ after LPS injection 
Fig. 1 AMPK $\operatorname{Thr}^{172}$ phosphorylation normalized to AMPK $\alpha 2$ protein content a before (pre-LPS) and $2 \mathrm{~h}$ after LPS ( $2 \mathrm{~h}$ LPS) and $\mathbf{b}$ before (PreExercise) and immediately after 10 min of one-legged knee extensor exercise (Post-Exercise). ACC Ser ${ }^{221}$ phosphorylation normalized to ACC2 protein content $\mathbf{c}$ pre-LPS and $2 \mathrm{~h}$ LPS as well as d Pre-Exercise and PostExercise. The results are presented as arbitrary units (AU). Values are mean \pm SE. $* P<0.05$, significantly different from pre-exercise

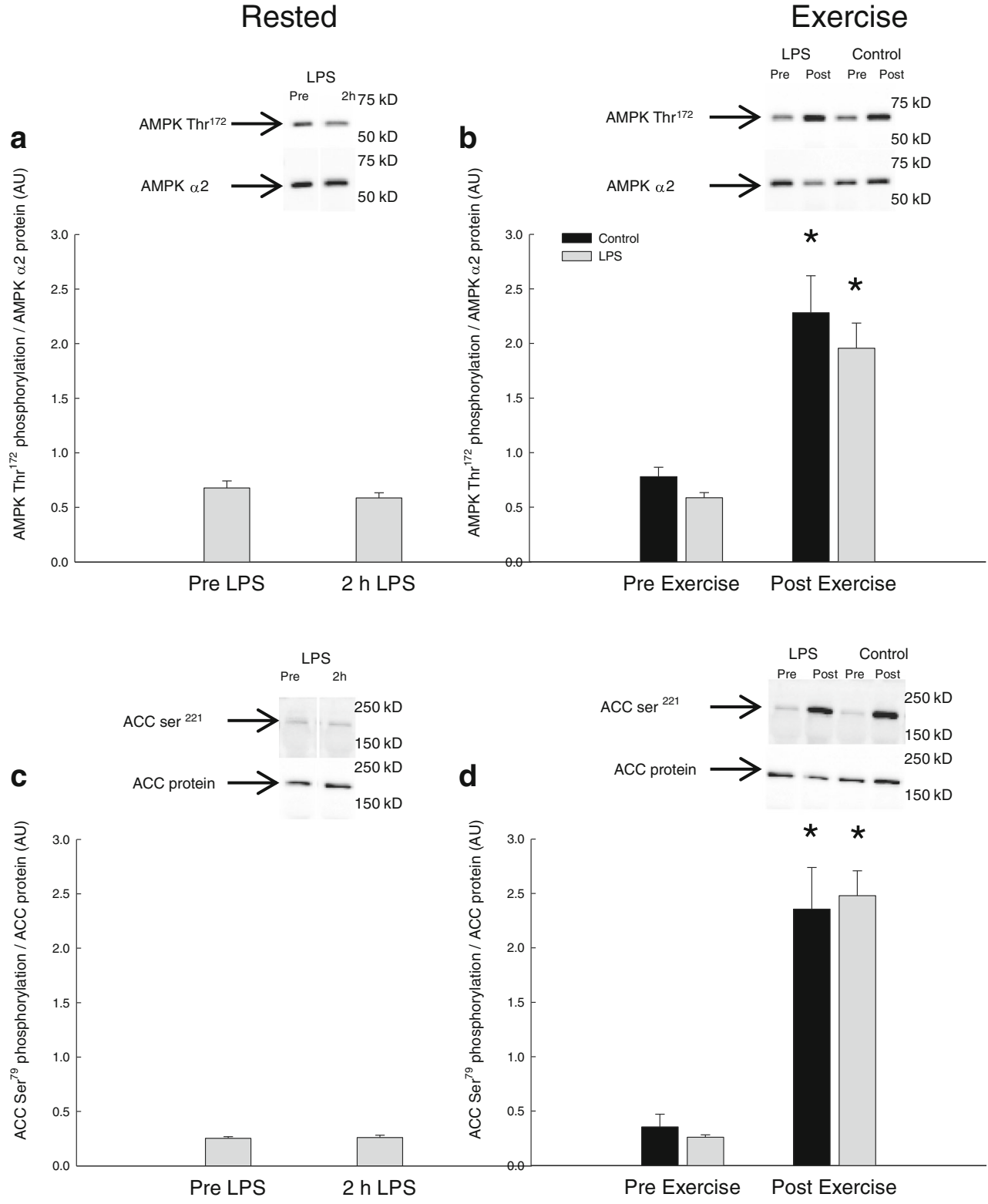

in the current study is different from previous observations in rats $[13,39,40]$. Hence $24 \mathrm{~h}$ of LPS infusion in rats has been shown to reduce the PDHa activity in skeletal muscle [13] and sepsis induced by repeated treatments with E. coli was associated with reduced concentration of active PDH in skeletal muscle [41]. The additional finding that treatment with TNF $\alpha$ binding protein prevented the $E$. coli-induced reduction in PDH activity suggested that TNF $\alpha$ is important in the LPSinduced effects on PDH during sepsis in rats [40]. Although the different observations may be due to species or model differences, it seems possible that the dose and the duration of treatment could be important. While a single injection of $0.3 \mathrm{ng} \mathrm{kg}^{-1}$ was used in the present study, effects on PDH were observed in rats with $24 \mathrm{~h}$ of LPS infusion resulting in an 8.9-fold increase in plasma $\mathrm{TNF} \alpha[2,13]$. In addition, while the present study did not observe any change in muscle lactate $2 \mathrm{~h}$ after the LPS injection, a previous rat study using a high dose of LPS infusion $\left(150 \mu \mathrm{g} \mathrm{kg}^{-1} \mathrm{~h}^{-1}\right)$ reported that muscle lactate increased after $2 \mathrm{~h}$ of LPS treatment [2] indicating that the inflammation inhibited the PDH. Taken together, this may suggest that potential effects of LPS-induced inflammation on $\mathrm{PDH}$ regulation evolve later than $2 \mathrm{~h}$ after injection. But future experiments are needed to confirm this in humans.

Previous studies have also indicated a link between TNF $\alpha$ and AMPK, although different effects have been reported. The unchanged AMPK phosphorylation $2 \mathrm{~h}$ after the LPS injection in the present human study is hence not in accordance with a previous study showing that treatment of muscle cells with TNF $\alpha$ decreased the AMPK activity [35]. The current finding is in line with previous observations in 
Fig. 2 PDH Ser ${ }^{293}$

phosphorylation normalized to PDH-E1 $\alpha$ protein content a before (pre-LPS) and $2 \mathrm{~h}$ after LPS ( $2 \mathrm{~h}$ LPS) and $\mathbf{b}$ before (PreExercise) and immediately after 10 min of one-legged knee extensor exercise (Post-Exercise). PDH Ser ${ }^{300}$ phosphorylation normalized to $\mathrm{PDH}-\mathrm{E} 1 \alpha$ protein content $\mathbf{c}$ pre-LPS and $2 \mathrm{~h}$ LPS as well as $\mathbf{d}$ Pre-Exercise and PostExercise. PDH site Ser ${ }^{295}$ phosphorylation normalized to $\mathrm{PDH}-$ E1 $\alpha$ protein content e pre-LPS and $2 \mathrm{~h}$ LPS as well as f PreExercise and Post-Exercise. The results are presented as arbitrary units (AU). Values are mean $\pm \mathrm{SE}$. ${ }^{*} P<0.05$, significantly different from Pre-Exercise
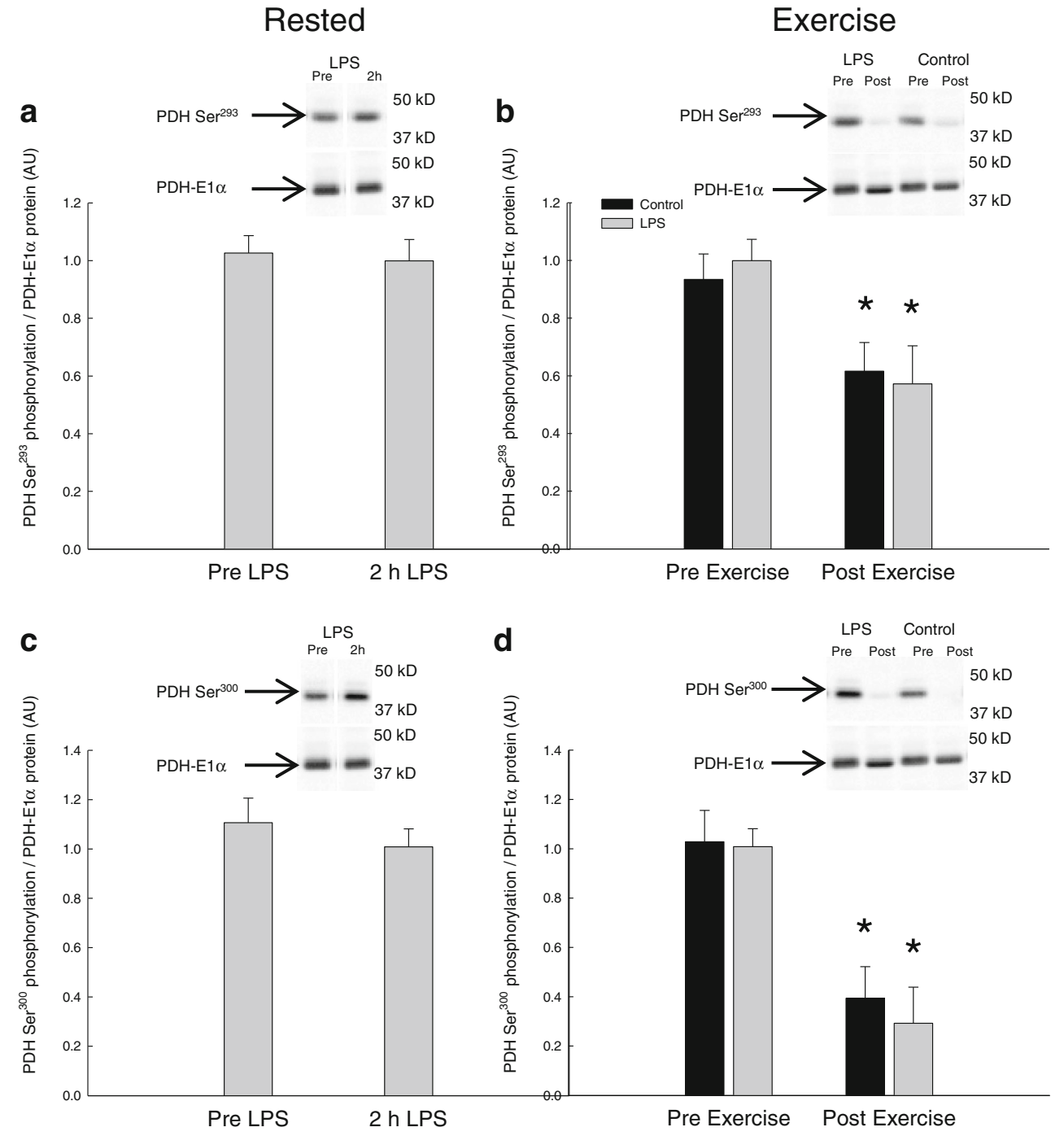

d
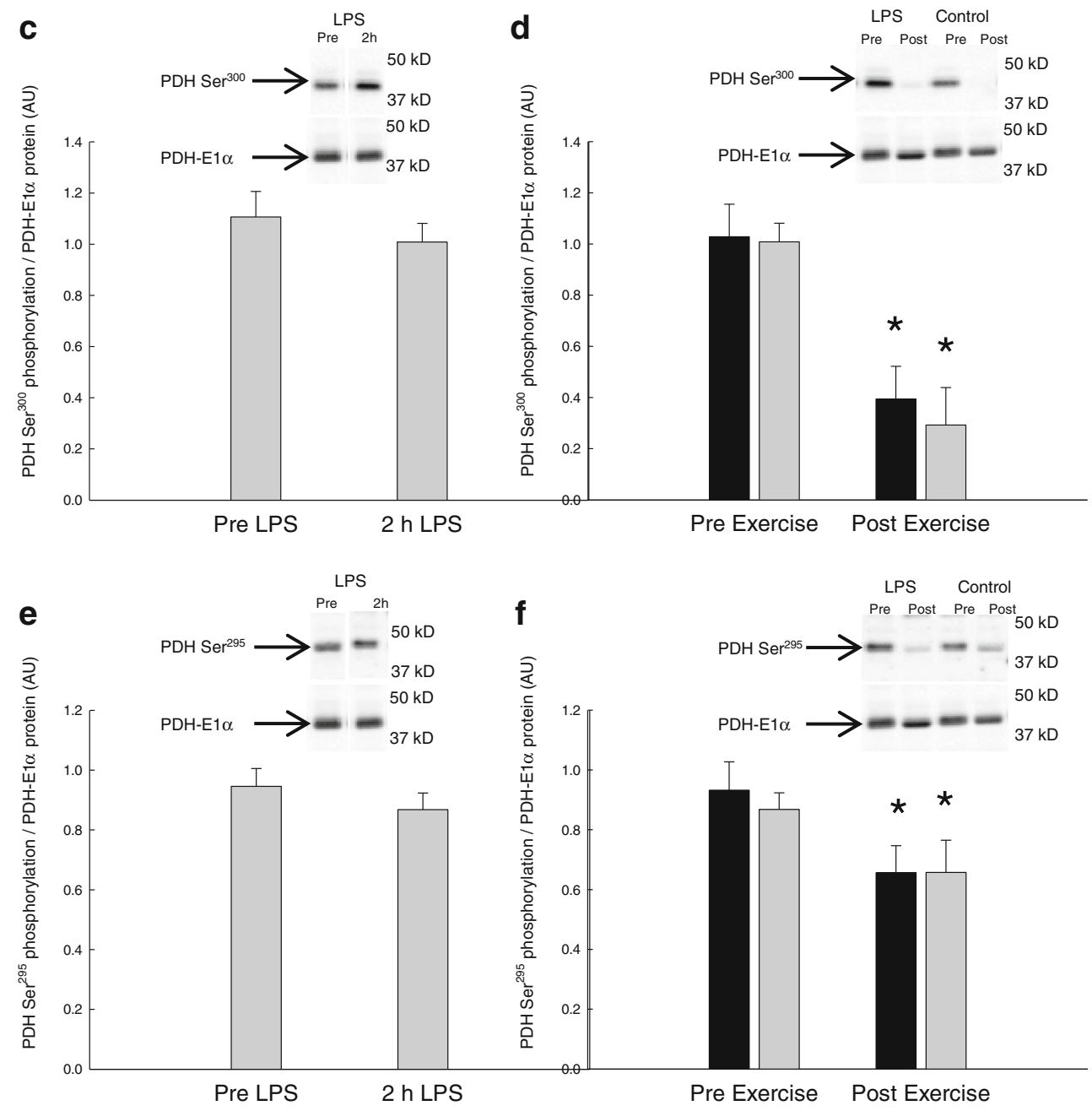

humans, although AMPK phosphorylation increased in human skeletal muscle $4 \mathrm{~h}$ after a single LPS injection [3]. This may suggest that the different observations are due to model differences and the present findings do not oppose the possibility that LPS-induced inflammation in humans increases AMPK phosphorylation in skeletal muscle. 
Rested

a

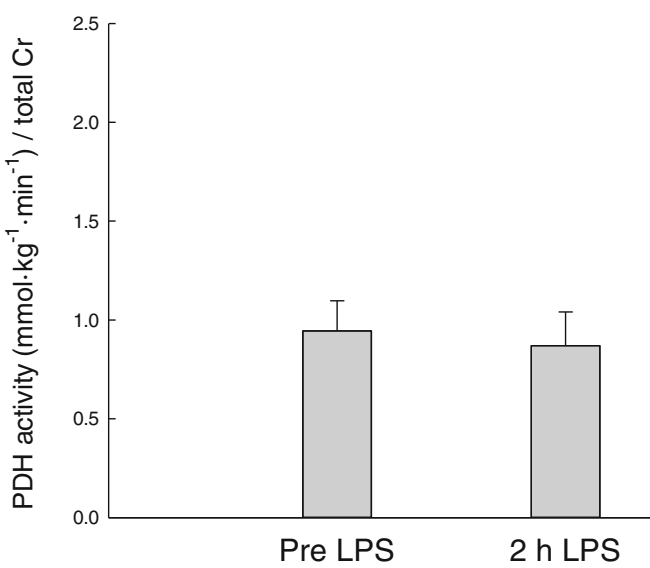

Fig. 3 PDHa activity ( $m m o l ~ \mathrm{~min}^{-1} \mathrm{~kg}^{-1}$ ) a before (pre-LPS) and $2 \mathrm{~h}$ after LPS ( $2 \mathrm{~h}$ LPS) and $\mathbf{b}$ before (Pre-Exercise) and immediately after $10 \mathrm{~min}$ of one-legged knee extensor exercise (Post-Exercise). The PDHa activity

The present study is (to our knowledge) the first to examine the impact of LPS-induced inflammation on exercise-induced metabolic regulation in humans. The exercise-induced decrease in PDH phosphorylation and increase in AMPK and ACC phosphorylation as well as in PDHa activity in the control trial are as expected based on many similar previous studies [20,21, $28,45]$. The present finding that the exercise-induced regulation of PDH, AMPK and ACC phosphorylation as well as PDHa activity was similar in the LPS trial, where TNF $\alpha$ was elevated, as in the control trial is however not as hypothesized. As PDH activation increases carbohydrate oxidation [31, 42] and AMPK-mediated ACC inactivation increases fat oxidation $[15,43]$, these observations suggest that human skeletal muscle maintains the ability to increase carbohydrate and fat oxidation in response to exercise despite the presence of short-term systemic inflammation. This conclusion is supported by the similar increase in the muscle lactate concentration in the two trials in the present study. In addition, it may be noted that while exercise induced a significant decrease in muscle glycogen and increase in muscle lactate in the control trials, these changes only tended to be significant in the LPS trial. This is opposite of expected based on previous animal LPS models indicating that inflammation results in elevated lactate production $[2,13]$. However, the lower statistical strength of the muscle glycogen and lactate changes in the LPS trial does not change the conclusion that short-term inflammation does not affect exercise-induced PDH and AMPK regulation in human skeletal muscle, but may suggest that inflammation affects the utilization of muscle glycogen. But this remains to be elucidated.

The lack of effect of inflammation on exercise-induced PDH and AMPK regulation suggests that exercise-induced metabolic flexibility is maintained during short-term inflammation, which is in contrast to previous studies showing that
Exercise

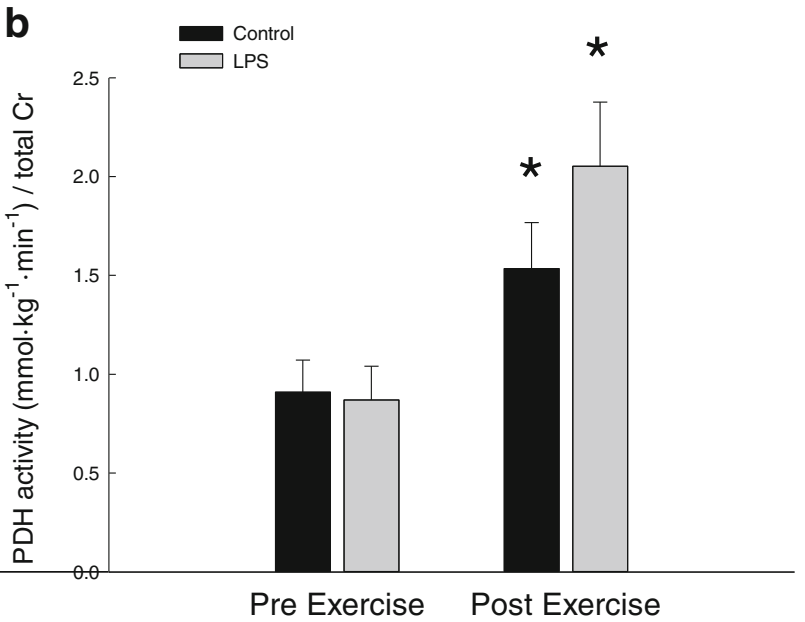

is normalized to total creatine in the samples. Values are mean $\pm \mathrm{SE}$. $* P<0.05$, significantly different from pre-exercise

elevated systemic TNF $\alpha$ levels [30] and a single LPS injection [1] induce whole-body insulin resistance in humans. These findings may suggest that insulin signaling and exerciseinduced metabolic regulation are affected differently by inflammation. However, it is important to note that the lack of effect on the exercise-induced responses was observed $2 \frac{1}{2} \mathrm{~h}$ after LPS injection, while the LPS-induced lowering of insulin sensitivity was demonstrated $420 \mathrm{~min}$ after LPS was injected. On the other hand, the previously reported TNF $\alpha$-induced insulin resistance was observed within $2 \mathrm{~h}$ of TNF $\alpha$ infusion with similar plasma levels of TNF $\alpha$ [30] as in the present study, while the previous LPS study resulted in more than 50fold higher plasma TNF $\alpha$ concentration [1] than in the present and previous TNF $\alpha$ study [30]. Although the TNF $\alpha$ infusion did result in a constant elevation in plasma $T N F \alpha$, while the present study induced a gradual increase in plasma $\mathrm{TNF} \alpha$, these considerations do support a different impact of TNF $\alpha$ on insulin-mediated glucose uptake than on exercise-induced AMPK and PDH regulation in human skeletal muscle.

As the purpose of the present study was to examine the potential effect of inflammation with elevated plasma TNF $\alpha$, the exercise bout was placed at the time point where the plasma TNF $\alpha$ concentration was expected to peak. In accordance, the observation that plasma TNF $\alpha$ was at a similar level (15-fold elevated) and not further increased at the sampling time point during exercise (approximately $2 \frac{1}{2} \mathrm{~h}$ after LPS injection) relative to $2 \mathrm{~h}$ after LPS is in line with previous studies showing that plasma TNF $\alpha$ peaks at approximately $2 \mathrm{~h}$ after a single LPS injection [1, 3, 5, 37]. However, it is certainly possible that more long-term inflammation with more sustained elevation in plasma TNF $\alpha$ will affect the exercise-induced AMPK and PDH regulation in skeletal muscle, but this remains to be determined. 
As previous studies examining the impact of LPS-induced inflammation and TNF $\alpha$ on PDH regulation have observed that a down-regulation of the PDHa activity was associated with increased PDK activity [39, 40] and PDK4 protein content [13], it may be that inflammation-induced effects on PDH regulation require changes in $\mathrm{PDK} 4$ expression, which may be obtained with high treatment dose and/or duration. The present observation that the lack of effect of inflammation on PDH regulation was associated with unchanged PDK4 protein content in skeletal muscle does support the possibility that changes in PDK4 protein underlie part of the effect of inflammation on $\mathrm{PDH}$.

In conclusion, a single LPS injection resulting in 17-fold increase in plasma TNF $\alpha$ concentration did not change AMPK and PDH phosphorylation and/or activity in human skeletal muscle at rest and did not affect exercise-induced AMPK and PDH regulation in human skeletal muscle. This suggests that the ability of skeletal muscle to increase glucose and fat oxidation during exercise is maintained during shortterm inflammation with elevated plasma TNF $\alpha$ levels. Hence, short-term low-grade inflammation does not seem to elicit metabolic inflexibility during exercise in humans as has been reported for insulin-stimulated glucose uptake at rest.

\begin{abstract}
Acknowledgement We would very much like to thank the subjects for the participation in the study. In addition, we are very grateful to Professor AF. Suffredini, National Institutes of Health, Bethesta, USA, for providing the LPS for the present study. The study was supported by The Danish Council for Independent Research, Danish Medical Research Council and The Danish Ministry of Culture for Sports Research. The Centre of Inflammation and Metabolism (CIM) is supported by a grant from the Danish National Research Foundation (DNRF55). The Centre for Physical Activity Research (CFAS) is supported by a grant from Trygfonden. CIM is part of the UNIK Project: Food, Fitness \& Pharma for Health and Disease, supported by the Danish Ministry of Science, Technology, and Innovation. CIM is a member of DD2-the Danish Centre for Strategic Research in Type 2 Diabetes (the Danish Council for Strategic Research, grant no. 09-067009 and 09-075724). The Copenhagen Muscle Research Centre (CMRC) is supported by a grant from the Capital Region of Denmark.
\end{abstract}

Open Access This article is distributed under the terms of the Creative Commons Attribution License which permits any use, distribution, and reproduction in any medium, provided the original author(s) and the source are credited.

\section{References}

1. Agwunobi AO, Reid C, Maycock P, Little RA, Carlson GL (2000) Insulin resistance and substrate utilization in human endotoxemia. $\mathrm{J}$ Clin Endocrinol Metab 85:3770-3778

2. Alamdari N, Constantin-Teodosiu D, Murton AJ, Gardiner SM, Bennett T, Layfield R, Greenhaff P (2008) Temporal changes in the involvement of pyruvate dehydrogenase complex in muscle lactate accumulation during lipopolysaccharide infusion in rats. J Physiol 586:1767-1775
3. Andreasen AS, Kelly M, Berg RM, Moller K, Pedersen BK (2011) Type 2 diabetes is associated with altered NF-kappab DNA binding activity, JNK phosphorylation, and AMPK phosphorylation in skeletal muscle after LPS. Plos One 6:e23999

4. Andreasen AS, Krabbe KS, Krogh-Madsen R, Taudorf S, Pedersen BK, Moller K (2008) Human endotoxemia as a model of systemic inflammation. Curr Med Chem 15:1697-1705

5. Andreasen AS, Pedersen-Skovsgaard T, Berg RM, Svendsen KD, Feldt-Rasmussen B, Pedersen BK, Moller K (2010) Type 2 diabetes mellitus is associated with impaired cytokine response and adhesion molecule expression in human endotoxemia. Intensive Care Med 36: $1548-1555$

6. Bach E, Nielsen RR, Vendelbo MH, Moller AB, Jessen N, Buhl M, Hafstrom T, Holm L, Pedersen SB, Pilegaard H, Bienso RS, Jorgensen JO, Moller N (2013) Direct effects of TNF-alpha on local fuel metabolism and cytokine levels in the placebo-controlled, bilaterally infused human leg: increased insulin sensitivity, increased net protein breakdown, and increased IL-6 release. Diabetes 62:40234029

7. Bergmeyer HU (1965) Methods of enzymatic analysis. Academic, London

8. Bergstrom J (1962) Muscle electrolytes in man. Scand JClin Lab Invest 68:1-110

9. Buhl M, Bosnjak E, Vendelbo MH, Gjedsted J, Nielsen RR, Hafstrom T, Vestergaard ET, Jessen N, Tonnesen E, Moller AB, Pedersen SB, Pilegaard H, Bienso RS, Jorgensen JO, Moller N (2013) Direct effects of locally administered lipopolysaccharide on glucose, lipid, and protein metabolism in the placebo-controlled, bilaterally infused human leg. J Clin Endocrinol Metab 98:2090-2099

10. Cederblad G, Carlin JI, Constantin-Teodosiu D, Harper P, Hultman E (1990) Radioisotopic assays of coash and carnitine and their acetylated forms in human skeletal muscle. Anal Biochem 185:274-278

11. Christensen E, Hansen O (1939) Untersuchungen über die verbrennungsvorgänge bei langdauernder, schwerer muskelabbeit. Skandinavisches archiv für physiologie 81:152-159

12. Constantin-Teodosiu D, Cederblad G, Hultman E (1991) A sensitive radioisotopic assay of pyruvate dehydrogenase complex in human muscle tissue. Anal Biochem 198:347-351

13. Crossland H, Constantin-Teodosiu D, Gardiner SM, Constantin D, Greenhaff PL (2008) A potential role for Akt/Foxo signalling in both protein loss and the impairment of muscle carbohydrate oxidation during sepsis in rodent skeletal muscle. J Physiol 586:5589-5600

14. Green CJ, Pedersen M, Pedersen BK, Scheele C (2011) Elevated NFkappab activation is conserved in human myocytes cultured from obese type 2 diabetic patients and attenuated by AMP-activated protein kinase. Diabetes 60:2810-2819

15. Hardie DG, Corton J, Ching YP, Davies SP, Hawley S (1997) Regulation of lipid metabolism by the AMP-activated protein kinase. Biochem Soc Trans 25:1229-1231

16. Harris RA, Bowker-Kinley MM, Huang B, Wu P (2002) Regulation of the activity of the pyruvate dehydrogenase complex. Adv Enzyme Regul 42:249-259

17. Hotamisligil GS, Shargill NS, Spiegelman BM (1993) Adipose expression of tumor necrosis factor-alpha: direct role in obesity-linked insulin resistance. Science 259:87-91

18. Howlett RA, Parolin ML, Dyck DJ, Hultman E, Jones NL, Heigenhauser GJ, Spriet LL (1998) Regulation of skeletal muscle glycogen phosphorylase and PDH at varying exercise power outputs. Am J Physiol 275:r418-r425

19. Kelley DE, Mandarino LJ (2000) Fuel selection in human skeletal muscle in insulin resistance: a reexamination. Diabetes 49:677-683

20. Kiilerich K, Gudmundsson M, Birk JB, Lundby C, Taudorf S, Plomgaard P, Saltin B, Pedersen PA, Wojtaszewski JF, Pilegaard H (2010) Low muscle glycogen and elevated plasma free fatty acid modify but do not prevent exercise-induced pdh activation in human skeletal muscle. Diabetes 59:26-32 
21. Kiilerich K, Ringholm S, Bienso RS, Fisher JP, Iversen N, Van HG, Wojtaszewski JF, Saltin B, Lundby C, Calbet JA, Pilegaard H (2011) Exercise-induced pyruvate dehydrogenase activation is not affected by 7 days of bed rest. J Appl Physiol 111:751-757

22. Linn TC, Pettit FH, Reed LJ (1969) Alpha-keto acid dehydrogenase complexes. X. Regulation of the activity of the pyruvate dehydrogenase complex from beef kidney mitochondria by phosphorylation and dephosphorylation. Proc Natl Acad Sci U S A 62:234-241

23. Mandarino LJ, Consoli A, Jain A, Kelley DE (1996) Interaction of carbohydrate and fat fuels in human skeletal muscle: impact of obesity and niddm. Am J Physiol 270:e463-e470

24. Passonneau JV, Lauderdale VR (1974) A comparison of three methods of glycogen measurement in tissues. Anal Biochem 60: 405-412

25. Pedersen BK (2009) The diseasome of physical inactivity — and the role of myokines in muscle - fat cross talk. J Physiol 587:5559-5568

26. Peters SJ, Harris RA, Wu P, Pehleman TL, Heigenhauser GJ, Spriet LL (2001) Human skeletal muscle PDH kinase activity and isoform expression during a 3-day high-fat/low-carbohydrate diet. Am J Physiol Endocrinol Metab 281:e1151-e1158

27. Peters SJ, St Amand TA, Howlett RA, Heigenhauser GJ, Spriet LL (1998) Human skeletal muscle pyruvate dehydrogenase kinase activity increases after a low-carbohydrate diet. Am J Physiol 275:e980-e986

28. Pilegaard H, Birk JB, Sacchetti M, Mourtzakis M, Hardie DG, Stewart G, Neufer PD, Saltin B, Van HG, Wojtaszewski JF (2006) PDHelalpha dephosphorylation and activation in human skeletal muscle during exercise: effect of intralipid infusion. Diabetes 55:3020-3027

29. Pilegaard H, Keller C, Steensberg A, Helge JW, Pedersen BK, Saltin B, Neufer PD (2002) Influence of pre-exercise muscle glycogen content on exercise-induced transcriptional regulation of metabolic genes. J Physiol 541:261-271

30. Plomgaard P, Bouzakri K, Krogh-Madsen R, Mittendorfer B, Zierath JR, Pedersen BK (2005) Tumor necrosis factor-alpha induces skeletal muscle insulin resistance in healthy human subjects via inhibition of Akt substrate 160 phosphorylation. Diabetes 54:2939-2945

31. Putman CT, Spriet LL, Hultman E, Lindinger MI, Lands LC, Mckelvie RS, Cederblad G, Jones NL, Heigenhauser GJ (1993) Pyruvate dehydrogenase activity and acetyl group accumulation during exercise after different diets. Am J Physiol 265:e752-e760

32. Randle PJ, Garland PB, Hales CN, Newsholme EA (1963) The glucose fatty-acid cycle. Its role in insulin sensitivity and the metabolic disturbances of diabetes mellitus. Lancet 1:785-789

33. Randle PJ, Sugden PH, Kerbey AL, Radcliffe PM, Hutson NJ (1978) Regulation of pyruvate oxidation and the conservation of glucose. Biochem Soc Symp 47-67

34. St Amand TA, Spriet LL, Jones NL, Heigenhauser GJ (2000) Pyruvate overrides inhibition of pdh during exercise after a lowcarbohydrate diet. Am J Physiol Endocrinol Metab 279:e275-e283
35. Steinberg GR, Michell BJ, Van Denderen BJ, Watt MJ, Carey AL, Fam BC, Andrikopoulos S, Proietto J, Gorgun CZ, Carling D, Hotamisligil GS, Febbraio MA, Kay TW, Kemp BE (2006) Tumor necrosis factor alpha-induced skeletal muscle insulin resistance involves suppression of AMP-kinase signaling. Cell Metab 4:465-474

36. Sutendra G, Dromparis P, Bonnet S, Haromy A, Mcmurtry MS, Bleackley RC, Michelakis ED (2011) Pyruvate dehydrogenase inhibition by the inflammatory cytokine TNFalpha contributes to the pathogenesis of pulmonary arterial hypertension. J Mol Med (Berl) 89:771-783

37. Taudorf S, Krabbe KS, Berg RM, Pedersen BK, Moller K (2007) Human models of low-grade inflammation: bolus versus continuous infusion of endotoxin. Clin Vaccine Immunol 14:250-255

38. Treebak JT, Frosig C, Pehmoller C, Chen S, Maarbjerg SJ, Brandt N, Mackintosh C, Zierath JR, Hardie DG, Kiens B, Richter EA, Pilegaard H, Wojtaszewski JF (2009) Potential role of tbc1d4 in enhanced post-exercise insulin action in human skeletal muscle. Diabetologia 52:891-900

39. Vary TC (1991) Increased pyruvate dehydrogenase kinase activity in response to sepsis. Am J Physiol 260:e669-e674

40. Vary TC, Hazen SA, Maish G, Cooney RN (1998) TNF binding protein prevents hyperlactatemia and inactivation of $\mathrm{PDH}$ complex in skeletal muscle during sepsis. J Surg Res 80:44-51

41. Vary TC, Martin LF (1993) Potentiation of decreased pyruvate dehydrogenase activity by inflammatory stimuli in sepsis. Circ Shock 39:299-305

42. Watt MJ, Heigenhauser GJ, Leblanc PJ, Inglis JG, Spriet LL, Peters SJ (2004) Rapid upregulation of pyruvate dehydrogenase kinase activity in human skeletal muscle during prolonged exercise. J Appl Physiol 97:1261-1267

43. Winder WW, Hardie DG (1996) Inactivation of acetyl-COA carboxylase and activation of AMP-activated protein kinase in muscle during exercise. Am J Physiol 270:e299-e304

44. Winder WW, Hardie DG (1999) AMP-activated protein kinase, a metabolic master switch: possible roles in type 2 diabetes. Am J Physiol 277:e1-e10

45. Wojtaszewski JF, Macdonald C, Nielsen JN, Hellsten Y, Hardie DG, Kemp BE, Kiens B, Richter EA (2003) Regulation of 5'amp-activated protein kinase activity and substrate utilization in exercising human skeletal muscle. Am J Physiol Endocrinol Metab 284:e813e822

46. Wu P, Sato J, Zhao Y, Jaskiewicz J, Popov KM, Harris RA (1998) Starvation and diabetes increase the amount of pyruvate dehydrogenase kinase isoenzyme 4 in rat heart. Biochem J 329(pt 1):197-201

47. Zell R, Geck P, Werdan K, Boekstegers P (1997) TNF-alpha and IL-1 alpha inhibit both pyruvate dehydrogenase activity and mitochondrial function in cardiomyocytes: evidence for primary impairment of mitochondrial function. Mol Cell Biochem 177:61-67 